Mach Bands

Quantitative Studies on Neural Networks in the Retina. By Dr. Floyd Ratliff. Pp. xii $+365 . \quad$ (San Francisco, London and Amsterdam: Holden-Day, Ine., 1965.) 15.25 dollars.

$\mathrm{T}$ HIS interesting and unusual book contains three main portions. The first is devoted to a most fascinating biography of Ernst Mach along with a description of his major contributions in the fields of philosophy, physics and biology. Ratliff shows how these interests in diverse fields were intertwinod and gives them a unity.

In the middle portion of Mach Bands the author lucidly describes Mach's original discovery of a most remarkable visual phenomenon-now called Mach bands. If the eye is prosented with a sudden chango in contrast gradiont, such as occurs with the diffuse shadow of an edge, the subject percoives a bright band where the gradient is negative and a dark band where the gradient is positivo. Mach could foresee that this was an important property of the visual nervous system and that it would enable the visual system to transmit information about the presence of contours. Almost a century had to pass before Ratliff and other neurophysiologists demonstrated the existence of this effect in single nerve fibres passing from the eye to the brain. Ratliff successfully attempts to integrato Mach's original psychophysical observations with our modern knowledge of neurophysiology and discusses the relevance of these findings to present-day theories of how we perceive detail.

The final portion of the book is a translation of the six relevant papers that Mach published between 1865 and 1906. In view of the present research interest in this field, these translations will form a most convenient reference source.

This book can be thoroughly recommended to all experimental psychologists and physiologists interested in the visual system, and to all those who have to use, or be aware of, some of the strange properties of the visual sense.

F. W. Campbell

\section{The Biliary System}

Edited by Dr. W. Taylor. (A Symposium of the NATO Advanced Study Institute.) Pp. xxv+712. (Oxford: Blackwell Scientific Publications, 1965.) 135s. net.

THE Biliary System is a report of a symposium held in Newcastle in the autumn of 1963 under the auspices of the North Atlantic Treaty Organization. The conference was attended by some ninety authorities on liver function from all over the world, and a high proportion of these presented communications to the conference.

The subjects were classified in eight main divisions commencing with structural and functional relationships of the liver and including various metabolic and clinical aspects of the subject. All the contributions are well written and illustrated and each one constitutes either an important new contribution to the subject or a valuable summary of the existing situation. Most of the papers have a short summary or conclusion at the end, but it would have been an improvement if this had been insisted on in each case.

With such a variety of papers it would be invidious to select any for special mention, but I was particularly impressed with the sections on biliary secretion in man and with that on bilirubin metabolism. The unexpected difference in the intestinal absorption of conjugated and unconjugated bilirubin is specially interesting in its relation to the biological purpose of conjugation, and the problem of cholestasis is well reviewed. New information on congenital, non-haemolytic jaundice is contributed by several authors.

The work concludes with a series of short summarizing articles by Prof. Sheila Sherlock, Dr. R. W. Brauer, Prof. W. H. H. Andrews and Dr. A. E. Doisy which give a very valuable perspective of the conference and should, perhaps, be read first. The book is extremely well produced and the whole production is a tribute to the organizing powers of Dr. W. Taylor, who acted as director of the conference; it should certainly be read by all interested in any aspect of liver function and represents good value at the price.

N. F. MACLAGAN

\section{Advances in Ecological Research}

Vol. 2. Edited by J. B. Cragg. Pp. xi+264. (London: Acadernic Press, Inc. (London), Ltd.; New York: Aeademie Press, Ine., 1964.) 57s. 6d.

HIS is a continuation of a series designed to provide biologists with a balanced view of recent developments in the ocological investigation of plants and animals. The volume consists of four substantial articles. In the first, M. E. Solomon considers the processes involved in the natural control of insects and mites, placing emphasis on the results of practical studies of population dynamics, the type of data required for the study of natural control and their analysis. Under the title "The Use of Statisties in Phytosociology", Lambert and Dale deal with the problem of putting the investigation of vogetation on an objective basis by the use of appropriate statistical techniques. The third article, by Bray and Gorham, is a report of thoir study on litter production in forests of the world. In this they discuss the components of litter, the factors affecting litter-fall and the seasonal changes in the standing crop of leaves. They conclude with a consideration of leaf litter as an index to net production. The final and by far the largest article is by HeslopHarrison, who reviews the development of concepts and methods in genecology during the preceding forty years.

Without exception the papers are well and attractively written and together constitute an important and stimulating contribution to the modern science of ecology.

K. JONES

\section{Preparation and Bio-Medical Application of Labelled Molecules}

Edited by J. Sirchis. (Proceedings of a Symposium sponsored by the Radiation Chemistry and Radioelements Centers of the Universities of Bologna, Padua and Rome; the Italian National Research Council; and the European Atomic Energy Community, Venice, August 23-29, 1964.) Pp. xviii + 502. (Brussels: European Atomic Energy Community, 1964.) n.p.

7 HIS is a compendium of information on the chemistry of isotopic labelling. Procedures are described for labelling specifically with radio-carbon and tritium a wide variety of substances at present of interest. The list includes several $\alpha$-amino-acids, $\gamma$-amino butyric acid, actinomycin, indan, cis-octenoic acid and nicotine. Recoil labelling and labelling by heterogeneous exchange on gas chromatographic columns are discussed in several articles, and also side reactions occurring during Wilzbach exchange labelling with tritium. Biosynthetic procedures are described for straight-chain hydrocarbons, terpenes, phytosterols, furocoumarins and plant hormones.

More than half the book is concerned with results of biological application of labelled substances. Winchell et al. (Berkeley) contribute an outstanding article on the kinetics of iodine-131 plasma proteins in dog lymph and Pinter (Baltimore) does the same for dog kidneys. Major articles by Tolbert et al. (Boulder) and Fish et al. (San Francisco) deal with results of metabolic studies based on measuring expired ${ }^{14} \mathrm{CO}_{2}$. Biancho et al. (Milan) attempt to correlate haem and globin specific activities, and Benassi and Piccotti (Turin) report on the incorporation of tritiated thymidine into ascites tumour cells. The articles are of a generally high standard, but any thread of continuity throughout the volume is scarcely perceptible.

A. S. McFartane 